\title{
Design of an effective automated machine for quality palm kernel production
}

\author{
M.O. Jimoh ${ }^{1 *}$ and O.J. Olukunle ${ }^{2}$ \\ ${ }^{I}$ (Department of Food Science and Technology, Bells University of Technology, Ota, Nigeria) \\ ${ }^{2}$ (Department of Agricultural Engineering, Federal University of Technology, Akure, Nigeria)
}

\begin{abstract}
Palm kernel production potentials of several countries are far from been fully exploited. At present, many countries are operating below expected capacity and this research effort is to develop an appropriate machine for quality production of palm kernel. Power requirement of the machine is $4.29 \mathrm{kw}$, resultant bending moment of the shaft is $4.67 \mathrm{Nm}$ and $85.30 \mathrm{Nm}$ and diameter of the shaft is $25.39 \mathrm{~mm}$. The machine is evaluated using 'Dura' variety at moisture content; $12.00 \%, 11.10 \%, 10.20 \%, 9.60 \%$ and $9.00 \%$, and 'Tenera' variety at; $12.00 \%, 11.00 \%, 10.00 \%, 9.10 \%$ and $8.20 \%$ moisture content. The performance of the machine shows that throughput capacity increases from 625-1270 kg/hr for 'Dura' and also increases from 750-1200 kg/hr for 'Tenera'. Mechanical damage reduces from 2.47-1.40\% for 'Dura' and reduces from 1.16-0.20\% for 'Tenera'. Functional efficiency increases from 92.30-96.40\% for 'Dura' and increases from 95.50-99.07\% for 'Tenera'. Quality performance efficiency increases from 91.00-95.30\% for 'Dura' and increases from 95.50-98.80\% for 'Tenera'. The mean shearing force in 'Dura' is $31.10 \pm 0.20 \mathrm{~N}$ and that of 'Tenera' is $12.66 \pm 0.20 \mathrm{~N}$.
\end{abstract}

Keywords - design, efficiency machine, palm kernel,

\section{Introduction}

Palm kernel stands at about 23\% potential from fresh fruit production in 1991 [1]. Several efforts have been developed towards an improved processing technique to increase production of good quality palm kernel and enhance export earnings. A prototype centrifugal palm nut cracker for horizontal shaft and vertical rotor type of National Centre for Agricultural Mechanization (NCAM) Ilorin was designed, fabricated and tested [2]. The design is based on centrifugal principle in which the nuts to be cracked are directed to rotor which hurls the nut and strikes it against a hard breaker plate. This machine is characterized with lot of damages to the kernel. A single-stage nut cracker as an integral component of the NIFOR small processing equipment was design and tested [3], the performance was limited and with very low capacity. The nut cracker is driven with the same prime mover as the horizontal digester; this is to reduce the cost of power. It was revealed [4] that cracking of wet nut from depericarper drum eliminate the requirement of nut silo, heater and fan, thus result in savings on capital investment, electrical power, steam consumption and maintenance cost. The mechanical damage of this is high and losses were incurred. Pretreatment of palm fruit [5] was reported to be a pre-condition for high efficiency in palm nut cracking. That is, smoothness of the shell, freedom of nuts from fibres and degree of shrinkage of the kernel. Thickness of the shell and regular feeding of nuts into the hopper and cracking chamber also have significant effect on the cracking. This research work armed at designing appropriate low cost palm nut cracker and evaluation of the machine on different varieties

\section{Machine Discription}

The machine consists of hopper, cracking chamber, a pair of hammer, transmission system, driving shaft, pulley and main frame. The hopper is calibrated and made from flat plate of $1 \mathrm{~mm}$ thickness in trapezoidal shape with upper dimension of $400 \mathrm{~mm}^{2}$ and lower dimension of $200 \mathrm{~mm}^{2}$ while its height is $400 \mathrm{~mm}$. It forms the feeding chute through which nuts are metered into the cracking chamber of the machine. The cracking chamber consists of a pair of hammer with (130x80x12) mm dimension made from mild steel. These are arranged at $180^{\circ}$ to each other. The driving mechanism consist of a v-belt, pulley and a single phase electric motor with power rating $5 \mathrm{kw}$ and speed $1840 \mathrm{rpm}$ while the designed power requirement is $4.29 \mathrm{kw}$ and with speed $1718 \mathrm{rpm}$. The designed shaft diameter is $25.39 \mathrm{~mm}$ but shaft with $25.00 \mathrm{~mm}$ diameter was selected. The machine has the ability to crack all varieties of palm nut with minimum damage to the kernel. The cost of the machine is within the buying capacity of local farmers and is simple to operate and maintain. 


\subsection{Determination of nut weight in hopper}

\section{Design Analysis}

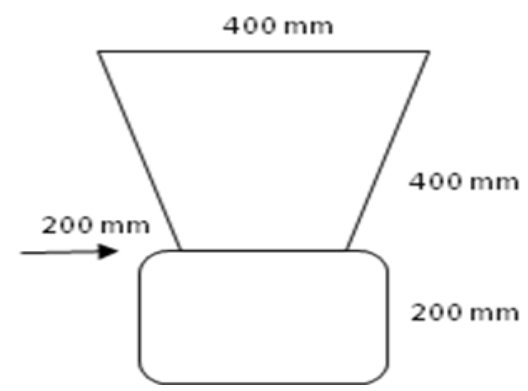

Figure1: schematic diagram of palm nut cracker

Area of the hopper $A=\left[\frac{0.20+0.40}{2}\right] 0.39$

Since the thickness of the plate is $3 \mathrm{~mm}$,

Therefore, volume of the hopper, $\mathrm{V}=400 \mathrm{~cm}^{3}$

But average volume of palm nut for tenera variety at $8.20 \%(d b)$ moisture content and with density of 1.02 $\mathrm{g} / \mathrm{cm}^{3}$ is $2.83 \mathrm{~cm}^{3}$ [6]. Number of palm nuts that will fill the hopper $=1500$

At $8.20 \%(d b)$ moisture content, mass $(\mathrm{m})$ of nut $=2.89 \mathrm{~g}$

Total mass of the nuts inside hopper $=4.34 \mathrm{~kg}$

$W_{n}=[m g]$

$\mathrm{W}_{\mathrm{n}}=42.58 \mathrm{~N}$

\subsection{Determination of hammer weight}

The length, breath and high dimension of the hammer is $0.13,0.08$ and $0.012 \mathrm{~m}$ respectively

Volume of the hammer $=12.48 \times 10^{-5} \mathrm{~m}^{3}$

But density of mild steel $=7850 \mathrm{~kg} / \mathrm{m}^{3}[7]$

$\mathrm{W}_{\mathrm{h}}=0.9797 \times 9.81=9.61 \mathrm{~N}$

Since a pair of hammer is required, $\mathrm{W}_{\mathrm{h}}=19.22 \mathrm{~N}$

\subsection{Determination of pulley weight}

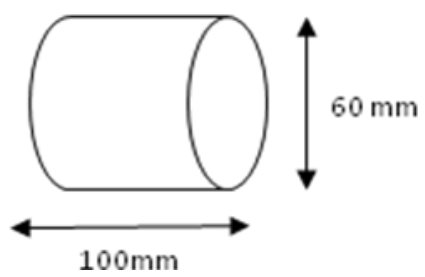

Figure 2: pulley and its dimensions

$V=\left[\pi r^{2} h\right]$

$=28.278 \times 10^{-5} \mathrm{~m}^{3}$

Therefore mass $(\mathrm{M})=2.22 \mathrm{~kg}$

Therefore weight of pulley $\left(\mathrm{W}_{\mathrm{p}}\right)=21.78 \mathrm{~N}$

\subsection{Determination of shaft weight}

Mass of the shaft $=1.2 \mathrm{~kg}$

Therefore weight $\left(\mathrm{W}_{\mathrm{s}}\right)$ of shaft $=11.77 \mathrm{~N}$

Forces (F) acting on the shaft are $\mathrm{W}_{\mathrm{n}}, \mathrm{W}_{\mathrm{h}}, \mathrm{W}_{\mathrm{p}}$ and $\mathrm{W}_{\mathrm{s}}$

Although, weight of shaft is distributed all over the surface of the shaft and acting at centre while weight of nut is evenly distributed over a length of $200 \mathrm{~mm}$ on one end of the shaft and acting at the centre of said distance.

Total forces acting on the shaft $=95.35 \mathrm{~N}$

The hurling speed of $30 \mathrm{~ms}^{-1}$ and $26 \mathrm{~ms}^{-1}$ were required to crack palm nut of minimum diameter less than or equal to $20 \mathrm{~mm}$ and greater than $20 \mathrm{~mm}$ respectively [2]. 
Power $p=[f v]$.

$=2.86 \mathrm{kw}$

Multiply by factor of safety of $1.5=4.29 \mathrm{kw}$

\subsection{Determination of included angle ( $\beta)$ and angle of wraps $(\alpha)$ in v-belt arrangement}

Centre distance $C=A+\left[\left(A^{2}+B^{2}\right)^{1 / 2}\right]$.....

Where $A=\left[L P / 4-\pi / 8\left(D_{1}-D_{2}\right)\right\rfloor$.

$$
B=\left[\left(D_{1}-D_{2}\right)^{2} / 8\right]
$$

Length of belt $(\mathrm{LP})=1500 \mathrm{~mm}$

Diameter of machine pulley $\left(\mathrm{D}_{1}\right) \quad=60 \mathrm{~mm}$

Diameter of electric motor pulley $\left(\mathrm{D}_{2}\right)=30 \mathrm{~mm}$

$\mathrm{A}=363.22 \mathrm{~mm}$

$\mathrm{B}=112.50 \mathrm{~mm}$

Therefore, $\mathrm{C}=743.46 \mathrm{~mm}$

$\cos \theta / 2=\left[\left(D_{1}-D_{2}\right) / C\right]$

$\theta=175.37^{0}$

$\operatorname{Sin} \beta=\left[\left(D_{1}-D_{2}\right) / C\right]$

$\beta=2.31^{0}$

Angle of wraps are calculated from

$\alpha_{1}=[180-2 \beta]$

$\alpha_{2}=[180+2 \beta]$.

\subsection{Determination of belt tensions}

$T_{1} / T_{2}=\left[\ell^{\mu \theta}\right]$

But $P=\left[\left(T_{1}-T_{2}\right) V\right]$

$\mu=0.21[8]$

$T_{C}=\left\lfloor 1 / 3 T_{1}\right\rfloor$

$\left(T_{1}-T_{C} /\left(T_{2}-T_{C}\right)=\left[\left(\ell^{\mu \theta / \operatorname{Sin} \theta / 2}\right)\right]\right.$

$\mathrm{T}_{1}=337.50 \mathrm{~N}$ and $\mathrm{T}_{2}=230.72 \mathrm{~N}$

\subsection{Design of Shaft}

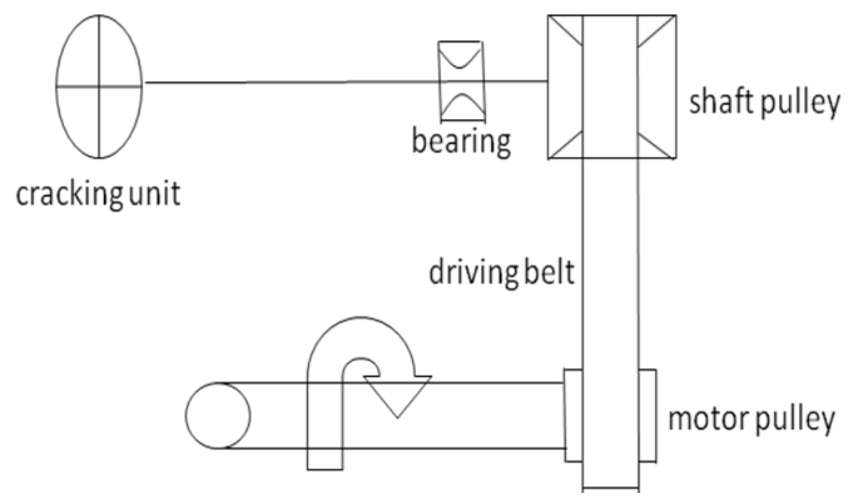

Figure 3: Schematic arrangement of belt drive 
Vertical forces acting on the shaft are:

i. Weight of nuts inside hopper acting within a length of $200 \mathrm{~mm}$

ii. Weight of shaft

iii. Weight of pulley

Length of shaft used $=400 \mathrm{~mm}$

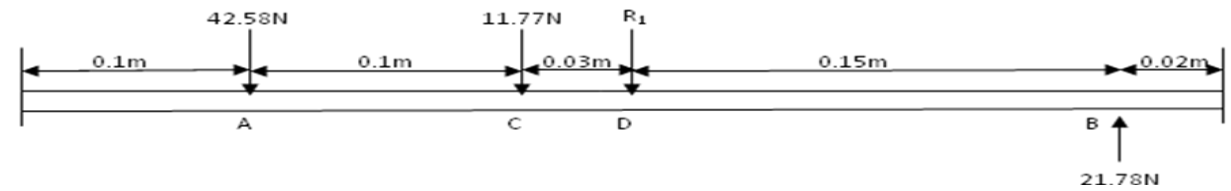

Taking moment about $\mathrm{A}$

$\mathrm{R}_{1}=37.85 \mathrm{~N}$

Vertical bending moment $\left(\mathrm{M}_{\mathrm{v}}\right)$ at point $\mathrm{A}$ and $\mathrm{B}=0$

At point $\mathrm{C}=42.58 \times 0.1$

$$
=4.26 \mathrm{Nm}
$$

At point $\mathrm{D}=21.78 \times 0.15$

$$
=3.27 \mathrm{Nm}
$$

Horizontal forces acting on the shaft are:

i Weight of a pair of hammer

ii Weight of shaft

iii Tension on the belt $\left(\mathrm{T}_{1}+\mathrm{T}_{2}\right)=568.22 \mathrm{~N}$

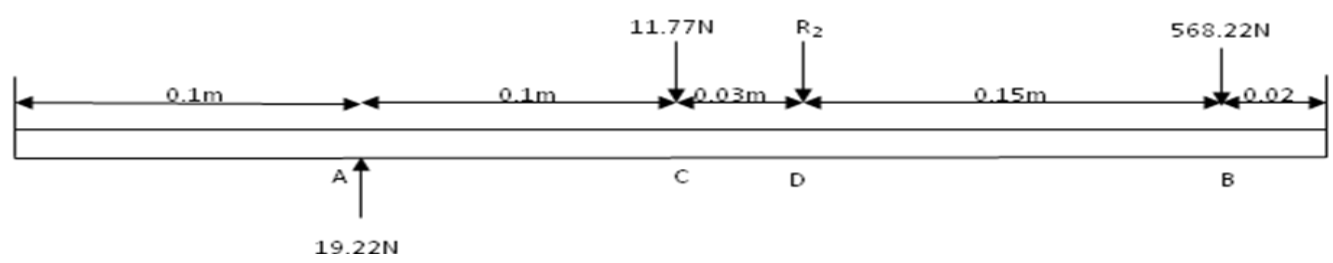

Taking moment about B

$$
\mathrm{R}_{2}=21.75 \mathrm{~N}
$$

Horizontal bending moment $\left(\mathrm{M}_{\mathrm{h}}\right)$ at point $\mathrm{A}$ and $\mathrm{B}=0$

At point $\mathrm{C}=19.22 \times 0.1$

$$
=1.92 \mathrm{Nm}
$$

At point $\mathrm{D}=568.22 \times 0.15$

$$
=85.23 \mathrm{Nm}
$$

Resultant bending moment $\left(\mathrm{M}_{\mathrm{b}}\right)$ at point $\mathrm{C}$

$M_{b}=\left[\left(M_{v}\right)^{2}+\left(M_{h}\right)^{2}\right]^{1 / 2}$.

$=\left[(4.26)^{2}+(1.92)^{2}\right]^{1 / 2}$

$=4.67 \mathrm{Nm}$

At point $\mathrm{D}$

$M_{b}=\left[\left(M_{v}\right)^{2}+\left(M_{h}\right)^{2}\right]^{1 / 2}$.

$=\left[(3.27)^{2}+(85.23)^{2}\right]^{1 / 2}$

$=85.30 \mathrm{Nm}$ 


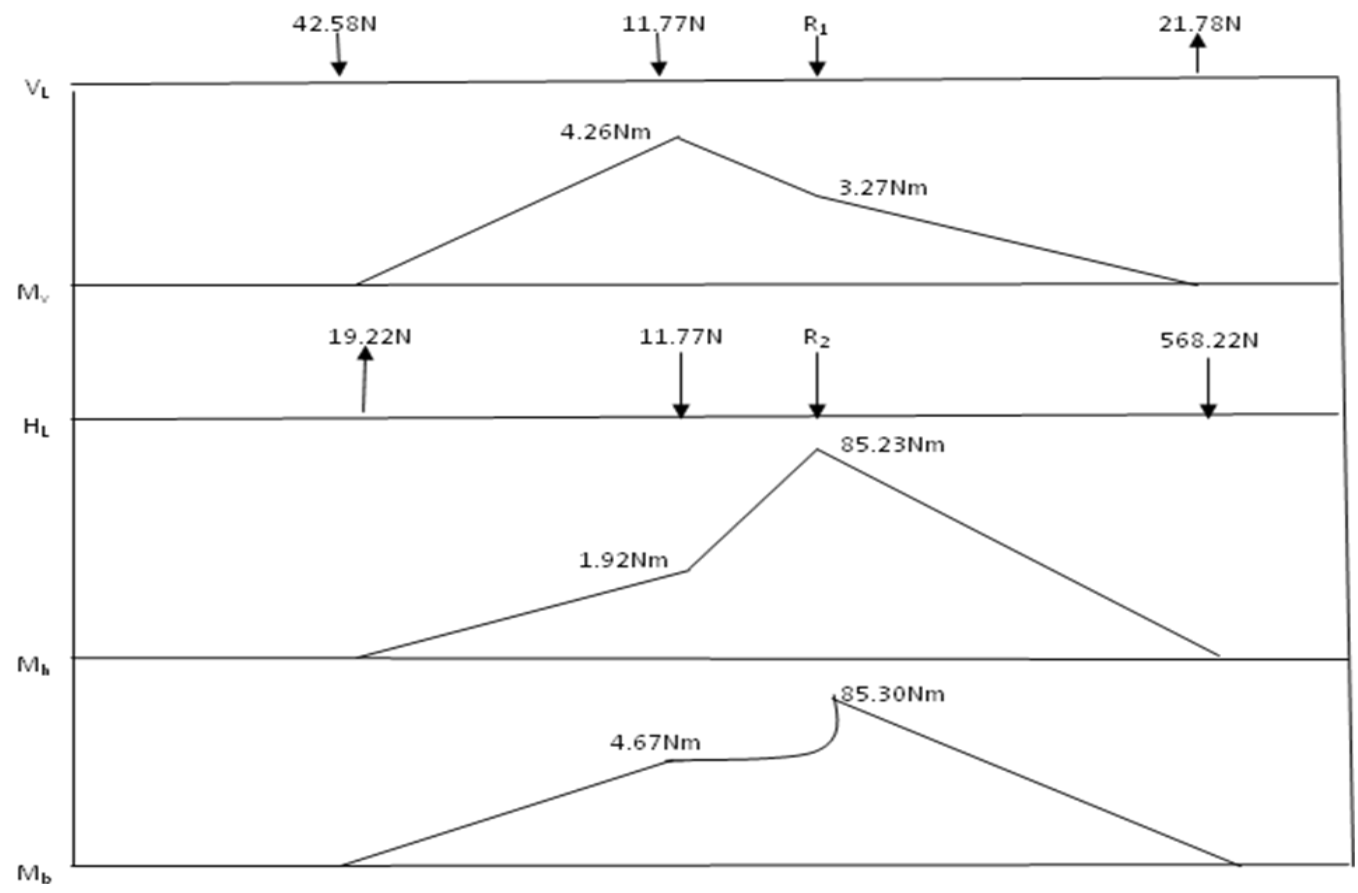

Figure 4: Free body and bending moment diagram of the shaft

Torsional moment $m_{t}=[p / 2 \pi n]$

Where $\mathrm{n}=$ speed $(\mathrm{rev} / \mathrm{hr})$

Maximum speed of the machine $=30 \mathrm{~m} / \mathrm{s}$

But $2(\mathrm{rad})=1 \mathrm{rev}$

Therefore, $30 \mathrm{~m} / \mathrm{s}=1718.18 \mathrm{rev} / \mathrm{min}$

Hence, $\mathrm{M}_{\mathrm{t}}=23.84 \mathrm{Nm}$

\subsection{Determination of Shaft Diameter}

$$
d^{3}=16 / \pi S s\left[\left(K_{b} M_{b}\right)^{2}+\left(K_{t} M_{t}\right)^{2}\right]^{1 / 2} \text {. }
$$

Where $\mathrm{d}=$ diameter of shaft

Ss = allowable stress $\left(55 \mathrm{MN} / \mathrm{m}^{2}\right.$ for shaft without keyway and $40 \mathrm{MN} / \mathrm{m}^{2}$ for shaft with keyway

$\mathrm{Kb}=$ factor for gradually applied load $=1.5$

$\mathrm{Kt}=$ factor for suddenly applied load $=1.5[9]$

\subsection{Determination of Torsional Rigidity of Shaft}

Based on the permissible angle of twist $\theta ; 0.3^{0} \leq \theta \leq 3^{0}$ depending on the application for solid circular shaft.

$\theta=\left[584 M_{t} L / G d^{4}\right]$

Where $\mathrm{L}=$ length of shaft in $(\mathrm{m})$

$\theta=2.03^{0}$

$\mathrm{G}=$ torsional modulus of elasticity, $\left(\mathrm{N} / \mathrm{m}^{2}\right)=7.30 \mathrm{GN} / \mathrm{m}^{2}$

\subsection{Determination of moisture content}

Sample of each variety was weighed separately in digital weighing balance and placed in the oven for one hour at 120 ${ }^{0} \mathrm{C}, 135{ }^{\circ} \mathrm{C}, 150{ }^{\circ} \mathrm{C}, 165{ }^{\circ} \mathrm{C}$ and $180{ }^{\circ} \mathrm{C}$ respectively. The moisture content ,Mc $(d b)$ of 'Dura' and 'Tenera' palm nut was determined by oven method using expression:

$\% M c(d b)=\left[\left(w_{1}-w_{2}\right) / w_{2}\right]$

Where: $d b$ is dry base, $\mathrm{w}_{1}$ is initial weight of the nut $(\mathrm{g})$ and $\mathrm{w}_{2}$ is final weight of the nut $(\mathrm{g})$. 


\subsection{Determination of palm nut shearing force}

Shearing force $f_{h}$ is obtained from the expression given by [6]:

$$
f_{h}=\frac{\prod}{8 L} l^{3} \delta_{s} f_{s}
$$

where: $f_{h}$ is shearing force in $\mathrm{N}, l$ is thickness of shell in $\mathrm{m}, L$ is dimension of pressure exerted during shearing in $\mathrm{m},{ }_{s}$ is allowable stress in $\mathrm{Nm}^{-2}$ and $f_{s}$ is compressive force in $\mathrm{N}$.

\section{Machine Performance Evaluation}

The machine was tested on treated varieties of palm nut at low machine speed. The effect of this treatment on machine parameters such as throughput capacity, functional efficiency, quality performance efficiency and mechanical damage were determined. During shearing, weight of nut fed into the hoper, weight of completely cracked nut, weight of unbroken kernel, weight of broken kernel, weight of partially and un-cracked nut were taken. Machine parameters are determined using the following expressions.

Throughput capacity $T_{c}=\left[W_{T} / T\right]$

Functional efficiency $E_{f}=\left[\frac{W_{C C}}{W_{L O}} \times 100\right]$

Quality performance efficiency $E_{p}=\left[\frac{W_{U}}{W_{L O}} \times 100\right]$

Mechanical damage $M_{d}=\left[\frac{W_{C C}-W_{U}}{W_{L O}} \times 100\right] \ldots$

Where: $\mathrm{W}_{\mathrm{T}}=$ Weight of nut fed into the hopper $/ \mathrm{kg}$

$\mathrm{T}=$ Time taken for the cracked mixture to completely leave the cracking chamber $/ \mathrm{hr}$

$\mathrm{W}_{\mathrm{cc}}=$ Weight of completely cracked nut $/ \mathrm{kg}$

$\mathrm{W}_{\mathrm{LO}}=$ weight of kernel for each loading $/ \mathrm{kg}$

$\mathrm{W}_{\mathrm{u}}=$ weight of unbroken kernel $/ \mathrm{kg}$

\section{Results And Discussion}

The moisture content of the nut decreases as temperature in the oven increases as shown in "Table" 1. At $120^{\circ} \mathrm{C} / \mathrm{hr}$, 'Dura' and 'Tenera' nut decreases to $12.0 \%(\mathrm{db})$; at $135{ }^{\circ} \mathrm{C} / \mathrm{hr}$, 'Dura' decreases to $11.1 \%(\mathrm{db})$ while 'Tenera' decreases to $11.0 \%(d b)$; at $150{ }^{\circ} \mathrm{C} / \mathrm{hr}$, 'Dura' decreases to $10.2 \%(d b)$ while 'Tenera' decreases to $10.0 \%(d b)$; at $165{ }^{\circ} \mathrm{C} / \mathrm{hr}$, 'Dura' decreases to $9.6 \%(d b)$ while 'Tenera' decreases to $9.1 \%(d b)$; and at 180 ${ }^{0} \mathrm{C} / \mathrm{hr}$, 'Dura' decreases to $9.0 \%(d b)$ while ;Tenera' also decreases to $8.2 \%(d b)$. As the moisture reduces, kernel loosed from shell, this create sufficient clearance between kernel and shell to absorb impact during cracking. As kernel shrinks, cracks are initiated in the shell due to thermal stress. At $180^{\circ} \mathrm{C} / \mathrm{hr}$, both varieties show tendency for flow of palm kernel oil (PKO) on shell surface. Shearing force increases as nut size increases; for 'Dura' variety, mean shearing force is $31.10 \pm 0.20 \mathrm{~N}$ and for 'Tenera' variety, mean shearing force is $12.66 \pm 0.20 \mathrm{~N}$ as shown in "Table" 2. The shearing force in 'Dura' variety is higher than that of 'Tenera' because of its shell thickness in accordance with [10].

Table 1: Determination of moisture content of 'Dura' and 'Tenera' nut

\begin{tabular}{|l|c|c|c|c|c|}
\hline $\begin{array}{l}\text { Palm nut } \\
\text { varieties }\end{array}$ & \multicolumn{5}{|c|}{ Moisture content (\%) } \\
\hline & $120^{\circ} \mathrm{C} / \mathrm{hr}$ & $135^{\circ} \mathrm{C} / \mathrm{hr}$ & $150^{\circ} \mathrm{C} / \mathrm{hr}$ & $165^{\circ} \mathrm{C} / \mathrm{hr}$ & $180^{\circ} \mathrm{C} / \mathrm{hr}$ \\
\hline Dura & 12.00 & 11.10 & 10.20 & 9.60 & 9.00 \\
\hline Tenera & 12.00 & 11.00 & 10.00 & 9.10 & 8.20 \\
\hline
\end{tabular}

Table 2: Determination of shearing force of palm nut varieties

\begin{tabular}{|l|c|c|c|}
\hline \multirow{2}{*}{} & No of observation & \multicolumn{2}{|c|}{ Shearing force $(\mathrm{N})$} \\
\cline { 3 - 4 } & & Dura & Tenera \\
\hline $0<\mathrm{d}_{1} \leq 0.50$ & 100 & - & $11.40 \pm 0.20$ \\
\hline $0.50<\mathrm{d}_{1} \leq 1.00$ & 100 & $29.00 \pm 0.20$ & $11.90 \pm 0.20$ \\
\hline
\end{tabular}


Design of an effective automated machine for quality palm kernel production

\begin{tabular}{|l|c|c|c|}
\hline $1.00<\mathrm{d}_{1} \leq 1.50$ & 100 & $29.70 \pm 0.20$ & $12.40 \pm 0.20$ \\
\hline $1.50<\mathrm{d}_{1} \leq 2.00$ & 100 & $30.80 \pm 0.20$ & $13.20 \pm 0.20$ \\
\hline $2.00<\mathrm{d}_{1} \leq 2.50$ & 100 & $32.20 \pm 0.20$ & $14.40 \pm 0.20$ \\
\hline $2.50<\mathrm{d}_{1} \leq 3.00$ & 100 & $33.80 \pm 0.20$ & - \\
\hline Mean value & 100 & $31.10 \pm 0.20$ & $12.66 \pm 0.20$ \\
\hline
\end{tabular}

Performance of the machine as shown in "Tables" 3 and 4 revealed that throughput capacity increases from $625.00 \mathrm{~kg} / \mathrm{hr}$ at $12.00 \%$ to $1270.00 \mathrm{~kg} / \mathrm{hr}$ at $9.00 \%$ moisture content for 'Dura' and also increases from $750.00 \mathrm{~kg} / \mathrm{hr}$ at $12.00 \%$ to $1200 \mathrm{~kg} / \mathrm{hr}$ at $8.20 \%$ moisture for 'Tenera'. Mechanical damage reduces from $2.47 \%$ at $12.00 \%$ to $1.40 \%$ at $9.00 \%$ moisture content for 'Dura' and reduces from $1.16 \%$ at $12.00 \%$ to $0.20 \%$ at $8.20 \%$ moisture content for 'Tenera'. Functional efficiency increases from $92.30 \%$ at $12.00 \%$ to $96.40 \%$ at $9.00 \%$ moisture for 'Dura' and increases from $95.50 \%$ at $12.00 \%$ to $99.07 \%$ at $8.20 \%$ moisture for 'Tenera'. Quality performance efficiency increases from $91.00 \%$ at $12.00 \%$ to $95.30 \%$ at $9.00 \%$ moisture for 'Dura' and increases from $95.50 \%$ at $12.00 \%$ to $98.80 \%$ at $8.20 \%$ moisture content for 'Tenera'. The performance of the machine on these varieties is in accordance with respective shell thickness [11].

Table 3: Machine performance evaluation using 'Dura' variety

\begin{tabular}{|c|c|c|c|c|c|}
\hline$M c(\%)$ & Size range $(\mathrm{cm})$ & $T_{c}(\mathrm{~kg} / \mathrm{hr})$ & $M_{d}(\%)$ & $E_{f}(\%)$ & $E_{p}(\%)$ \\
\hline 12.00 & $0.50<\mathrm{d}_{1} \leq 1.00$ & 625.00 & 2.47 & 92.30 & 91.00 \\
\hline & $1.00<\mathrm{d}_{1} \leq 1.50$ & 625.00 & 2.47 & 92.30 & 91.00 \\
\hline & $1.50<\mathrm{d}_{1} \leq 2.00$ & 685.00 & 2.46 & 92.31 & 91.00 \\
\hline & $2.00<\mathrm{d}_{1} \leq 2.50$ & 750.00 & 2.46 & 92.32 & 91.01 \\
\hline & $2.50<\mathrm{d}_{1} \leq 3.00$ & 800.00 & 2.46 & 92.32 & 91.02 \\
\hline & $0.50<\mathrm{d}_{1} \leq 1.00$ & 700.00 & 2.22 & 92.88 & 91.65 \\
\hline & $1.00<\mathrm{d}_{1} \leq 1.50$ & 730.00 & 2.22 & 92.88 & 91.65 \\
\hline & $1.50<\mathrm{d}_{1} \leq 2.00$ & 780.00 & 2.21 & 92.88 & 91.65 \\
\hline & $2.00<\mathrm{d}_{1} \leq 2.50$ & 850.00 & 2.21 & 92.89 & 91.66 \\
\hline & $2.50<\mathrm{d}_{1} \leq 3.00$ & 900.00 & 2.21 & 92.89 & 91.66 \\
\hline & $0.50<\mathrm{d}_{1} \leq 1.00$ & 725.00 & 1.98 & 93.52 & 92.94 \\
\hline & $1.00<\mathrm{d}_{1} \leq 1.50$ & 760.00 & 1.98 & 93.52 & 92.94 \\
\hline & $1.50<\mathrm{d}_{1} \leq 2.00$ & 800.00 & 1.97 & 93.52 & 92.94 \\
\hline & $2.00<\mathrm{d}_{1} \leq 2.50$ & 900.00 & 1.97 & 93.53 & 92.95 \\
\hline & $2.50<\mathrm{d}_{1} \leq 3.00$ & 920.00 & 1.96 & 93.54 & 92.95 \\
\hline & $0.50<\mathrm{d}_{1} \leq 1.00$ & 700.00 & 1.54 & 95.66 & 94.38 \\
\hline & $1.00<\mathrm{d}_{1} \leq 1.50$ & 800.00 & 1.54 & 95.66 & 94.38 \\
\hline & $1.50<\mathrm{d}_{1} \leq 2.00$ & 900.00 & 1.54 & 95.67 & 94.38 \\
\hline & $2.00<\mathrm{d}_{1} \leq 2.50$ & 1000.00 & 1.53 & 95.67 & 94.38 \\
\hline & $2.50<\mathrm{d}_{1} \leq 3.00$ & 120.00 & 1.52 & 95.68 & 94.40 \\
\hline & $0.50<\mathrm{d}_{1} \leq 1.00$ & 700.00 & 1.41 & 96.38 & 95.28 \\
\hline & $1.00<\mathrm{d}_{1} \leq 1.50$ & 800.00 & 1.41 & 96.40 & 95.28 \\
\hline & $1.50<\mathrm{d}_{1} \leq 2.00$ & 900.00 & 1.41 & 96.40 & 95.29 \\
\hline & $2.00<\mathrm{d}_{1} \leq 2.50$ & 1100.00 & 1.40 & 96.40 & 95.30 \\
\hline & $2.50<\mathrm{d}_{1} \leq 3.00$ & 1270.00 & 1.40 & 96.40 & 95.30 \\
\hline
\end{tabular}

Table 4: Machine performance evaluation using 'Tenera' variety

\begin{tabular}{|l|l|l|c|c|c|}
\hline$M c(\%)$ & $\begin{array}{l}\text { Size range } \\
(\mathrm{cm})\end{array}$ & $T_{c}(\mathrm{~kg} / \mathrm{hr})$ & $M_{d}(\%)$ & $E_{f}(\%)$ & $E_{p}(\%)$ \\
\hline 12.00 & $0.00<\mathrm{d}_{1} \leq 0.50$ & 750.00 & 1.16 & 95.50 & 95.50 \\
\hline & $\begin{array}{l}0.50<\mathrm{d}_{1} \leq \\
1.00\end{array}$ & 760.00 & 1.16 & 95.50 & 95.50 \\
\hline & $1.00<\mathrm{d}_{1} \leq 1.50$ & 800.00 & 1.17 & 95.50 & 95.50 \\
\hline & $1.50<\mathrm{d}_{1} \leq 2.00$ & 820.00 & 1.18 & 95.51 & 95.50 \\
\hline & $\begin{array}{l}2.00<\mathrm{d}_{1} \leq \\
2.50\end{array}$ & 830.00 & 1.18 & 95.51 & 95.51 \\
\hline & $0.00<\mathrm{d}_{1} \leq 0.50$ & 800.00 & 1.12 & 96.00 & 95.82 \\
\hline
\end{tabular}


Design of an effective automated machine for quality palm kernel production

\begin{tabular}{|c|c|c|c|c|c|}
\hline \multicolumn{6}{|c|}{11.00} \\
\hline & $\begin{array}{l}0.50<\mathrm{d}_{1} \leq \\
1.00\end{array}$ & 820.00 & 1.12 & 96.00 & 95.82 \\
\hline & $1.00<\mathrm{d}_{1} \leq 1.50$ & 850.00 & 1.13 & 96.00 & 95.82 \\
\hline & $1.50<\mathrm{d}_{1} \leq 2.00$ & 900.00 & 1.13 & 96.01 & 95.83 \\
\hline & $\begin{array}{l}2.00<\mathrm{d}_{1} \leq \\
2.50\end{array}$ & 900.00 & 1.13 & 96.02 & 95.83 \\
\hline \multirow{5}{*}{10.00} & $0.00<\mathrm{d}_{1} \leq 0.50$ & 850.00 & 1.04 & 96.96 & 96.46 \\
\hline & $\begin{array}{l}0.50<\mathrm{d}_{1} \leq \\
1.00\end{array}$ & 860.00 & 1.04 & 96.96 & 96.46 \\
\hline & $1.00<\mathrm{d}_{1} \leq 1.50$ & 880.00 & 1.04 & 96.96 & 96.47 \\
\hline & $1.50<\mathrm{d}_{1} \leq 2.00$ & 950.00 & 1.05 & 96.98 & 96.47 \\
\hline & $\begin{array}{l}2.00<\mathrm{d}_{1} \leq \\
2.50\end{array}$ & 960.00 & 1.05 & 96.98 & 96.47 \\
\hline \multirow{5}{*}{9.10} & $0.00<\mathrm{d}_{1} \leq 0.50$ & 850.00 & 0.30 & 98.43 & 98.11 \\
\hline & $\begin{array}{l}0.50<\mathrm{d}_{1} \leq \\
1.00\end{array}$ & 880.00 & 0.30 & 98.43 & 98.12 \\
\hline & $1.00<\mathrm{d}_{1} \leq 1.50$ & 900.00 & 0.30 & 98.43 & 98.12 \\
\hline & $1.50<\mathrm{d}_{1} \leq 2.00$ & 1000.00 & 0.30 & 98.44 & 98.12 \\
\hline & $\begin{array}{l}2.00<\mathrm{d}_{1} \leq \\
2.50\end{array}$ & 1200.00 & 0.30 & 98.45 & 98.12 \\
\hline \multirow[t]{5}{*}{8.20} & $0.00<\mathrm{d}_{1} \leq 0.50$ & 860.00 & 0.20 & 99.06 & 98.78 \\
\hline & $\begin{array}{l}0.50<\mathrm{d}_{1} \leq \\
1.00\end{array}$ & 900.00 & 0.20 & 99.06 & 98.78 \\
\hline & $1.00<\mathrm{d}_{1} \leq 1.50$ & 900.00 & 0.20 & 99.06 & 98.79 \\
\hline & $1.50<\mathrm{d}_{1} \leq 2.00$ & 1100.00 & 0.20 & 99.07 & 98.80 \\
\hline & $\begin{array}{l}2.00<\mathrm{d}_{1} \leq \\
2.50\end{array}$ & 1200.00 & 0.20 & 99.07 & 98.80 \\
\hline
\end{tabular}

\section{Conclusions And Recommendation}

The following conclusions and recommendation are drawn from this work:

1. The shaft of the machine twists at angle $2.03^{\circ}$ and can withstand both gradual and sudden loading.

2. The machine can produce an average kernel to the ton of 6.72 tons of tenera variety /8 working hours and 4.06 tons of dura variety/ 8 working hours. The machine is therefore recommended for small and medium scale industries.

3. Heat treatment of palm nut to reduce its moisture content pave the way for appropriate design of palm nut handling machine and with minimum mechanical damage. However, 85\% nuts have an existing crack when fully dried

4. The choice of transmission system for effective quality production was on the basis of shearing force.

\section{References}

[1] Food and Agricultural Organization, Trade year book, Journal for Food and Agricultural Organization 56(1), 2002, 174-175.

[2] O.O. Babatunde, and J.O Okoli, Investigation into the effect of nut size on the speed needed for cracking palm nut in centrifugal nut cracker, Nigeria Journal of Palm and Oil Seeds, 9(1,) 1988, 84-88.

[3] C.O. Ilechie, $22^{\text {nd }}$ annual report of NIFOR, Journal of Nigerian Institute for Oil Palm Research, Benin City, Nigeria, 1985, 92-94.

[4] Ch. Wang, and Y.W. Mai, Deformation and fracture of macadamia nuts part 1: microstructure and fracture mechanics analysis of nut shell, International Journal of Fracture, 69(1), 1994, 1051-1055.

[5] S.T. Olayiwola, Design and construction of palm nut cracker. Nigeria Journal of Palm and Oil Seeds, 9(1), 1988, 18-19.

[6] M.O. Jimoh, and O.J. Olukunle, Effect of heat treatment during mechanical cracking using varieties of palm nut, Agric. Eng Int: CIGR Journal 14(3), 2012, 168-174.

[7] O.J. Olukunle, Grain damage and threshing efficiency of an indigenous combine harvester, International Agricultural Engineering Journal, 11(1), 2002, 51-58.

[8] J.A. Akpobi, and A.A. Oniah, Design and manufacturing of a palm fruit digester screw press, Nigeria Journal of Engineering management, 10(2), 2009, 10-19.

[9] O.C. Ademosun, Performance evaluation of cocao dehauling and winnowing machine, AMA, 24(3), 1993, 5-13. 
[10] O.J. Olukunle, M.O. Jimoh, and A.O. Atere, Development and performance evaluation of a motorized palm nut cracker, Journal of Engineering and Engineering Technology, 6(1), 2008, PP 45-55.

[11] P.J. Fellow, Food processing technology: Principles and Practice (England, Wood-head Publishers Limited, 2003).

\section{NOMENCLATURE}

$W_{n}=$ weight of nut, $\mathrm{N}$

$W_{h}=$ weight of hammer, $\mathrm{N}$

$W_{p}=$ weight of pulley, $\mathrm{N}$

$W_{s}=$ weight of shaft, $\mathrm{N}$

$P=$ Power requirement of the machine, kw

$\beta=$ included angle of the transmission belt, $\left({ }^{\circ}\right)$

$\alpha=$ angle of wraps of belt belt, $\left({ }^{\circ}\right)$

$T=$ belt tension, $\mathrm{N}$

$M_{v}=$ vertical bending moment of the shaft, $\mathrm{Nm}$

$M_{h}=$ horizontal bending moment of the shaft, $\mathrm{Nm}$

$M_{b}=$ resultant bending moment of the shaft, $\mathrm{Nm}$

$M_{t}=$ torsional moment of the shaft, $\mathrm{Nm}$

$S_{s}=$ allowable stress of the shaft, $\mathrm{N} / \mathrm{m}^{2}$

$d=$ diameter of the shaft, $\mathrm{m}$

$\theta=$ angle of twist of the shaft, $\left({ }^{\circ}\right)$

$\mathrm{G}=$ torsional modulus of elasticity, $\mathrm{N} / \mathrm{m}^{2}$

$\mathrm{E}_{\mathrm{f}}=$ functional efficiency, $\%$

$\mathrm{E}_{\mathrm{p}}=$ quality performance efficiency, \%

$\mathrm{M}_{\mathrm{d}}=$ mechanical damage, $\%$

$\mathrm{W}_{\mathrm{CC}}=$ weight of completely cracked kernel, $\mathrm{kg}$

$\mathrm{W}_{\mathrm{LO}}=$ weight of kernel for each loading, $\mathrm{kg}$

$\mathrm{W}_{\mathrm{U}}=$ weight of unbroken kernel, $\mathrm{kg}$ 